BMJ Open

Diabetes

Research

\& Care

\title{
Diabetes mellitus as a risk factor for compression neuropathy: a longitudinal cohort study from southern Sweden
}

\author{
Mattias Rydberg (D) ,1,2 Malin Zimmerman, ${ }^{1,2}$ Anders Gottsäter, ${ }^{3}$ Peter M Nilsson, ${ }^{4,5}$ \\ Olle Melander, ${ }^{4,5}$ Lars B Dahlin ${ }^{1,2}$
}

To cite: Rydberg M, Zimmerman M, Gottsäter A, et al. Diabetes mellitus as a risk factor for compression neuropathy: a longitudinal cohort study from southern Sweden. BMJ Open Diab Res Care 2020;8:e001298. doi:10.1136/ bmjdrc-2020-001298

Received 19 February 2020 Revised 26 March 2020 Accepted 28 March 2020

Check for updates

\section{(c) Author(s) (or their} employer(s)) 2020. Re-use permitted under CC BY-NC. No commercial re-use. See rights and permissions. Published by BMJ.

${ }^{1}$ Department of Translational Medicine - Hand Surgery, Lund University, Malmö, Sweden ${ }^{2}$ Department of Hand Surgery, Skånes Universitetssjukhus Malmö, Malmö, Sweden ${ }^{3}$ Department of Vascular Diseases, Skånes Universitetssjukhus Malmö, Malmö, Sweden

${ }^{4}$ Department of Clinical Sciences, Lund University, Skåne University Hospital, Malmö, Sweden

${ }^{5}$ Department of Internal Medicine, Clinical Research Unit, Lund University, Malmö, Sweden

Correspondence to Dr Mattias Rydberg; mattias.rydberg@med.lu.se

\section{ABSTRACT}

Introduction Compression neuropathies (CN) in the upper extremity, the most common being carpal tunnel syndrome (CTS) and ulnar nerve entrapment (UNE), are frequent among patients with diabetes mellitus (DM). Earlier studies have shown contradicting results regarding DM as a risk factor for $\mathrm{CN}$. Thus, the aim of the present populationbased, longitudinal study was to explore potential associations between DM, CTS, and UNE during long-term follow-up.

Research design and methods $A$ total of 30466 participants aged $46-73$ years, included in the populationbased Malmö Diet and Cancer Study during 1991-1996, were followed up in Swedish national registries regarding incident CTS and UNE until 2016. Associations between prevalent DM at baseline and incident CTS or UNE were calculated using Cox proportional hazard models, adjusted for baseline confounders, such as sex, age at study entry, smoking, hypertension, use of antihypertensive treatment, alcohol consumption, and body mass index (BMI). HbA1C and fasting plasma glucose levels had been measured at baseline in a subgroup of 5508 participants and were related to incident CTS and UNE in age and sex-adjusted binary logistic regression models.

Results A total of 1081 participants developed CTS and 223 participants developed UNE during a median followup of 21 years. Participants with incident CTS or UNE had higher prevalence of DM and higher BMI at baseline. Using multivariate Cox regression models, prevalent DM at baseline was independently associated with both incident CTS (HR 2.10; 95\% Cl 1.65 to 2.70, $p<0.0001$ ) and incident UNE (HR 2.20; $95 \% \mathrm{Cl} 1.30$ to $3.74, \mathrm{p}=0.003$ ). Higher levels of HbA1c and plasma glucose were associated with an increased risk for CTS, but not for UNE.

Conclusion This study establishes DM as a major risk factor in the development of both CTS and UNE. Furthermore, a higher BMI is associated with both CTS and UNE. Finally, hyperglycemia seems to affect the median and ulnar nerves differently.

\section{INTRODUCTION}

Diabetes mellitus (DM) is a rapidly growing global health issue, with an estimated prevalence of 420 million people or $9 \%$ globally in 2014. ${ }^{1}$ With 23 million incident cases every year, the burden of the disease is growing fast. $^{2}$

\section{Significance of this study}

What is already known about this subject?

- Cross-sectional and case-control studies have proposed diabetes mellitus (DM) as a risk factor for carpal tunnel syndrome.

- Less is known about risk factors for the development of ulnar nerve entrapment.

- There is lack of supporting evidence from longitudinal data regarding risk factors for compression neuropathies.

\section{What are the new findings?}

- Longitudinal data from over 20 years of follow-up suggest that DM is a major risk factor for both ulnar nerve entrapment and carpal tunnel syndrome.

- Hyperglycemia seems to affect the ulnar and median nerves differently.

- A high body mass index seems to increase the risk for both carpal tunnel syndrome and ulnar nerve entrapment.

How might these results change the focus of research or clinical practice?

- These results highlight that diabetic complications not only affect the cardiovascular, renal and eye systems, but also the peripheral nervous system.

- With an alarming global incidence rate of DM, intensified primary prevention and relevant patient information are more important than ever to prevent compression neuropathies.

Compression neuropathies $(\mathrm{CN})$ in the upper extremity, the most common being carpal tunnel syndrome (CTS), followed by ulnar nerve entrapment (UNE) at the elbow, have been thoroughly researched both in the presence of DM and without. ${ }^{34}$ Nevertheless, there are still contradicting results regarding $\mathrm{DM}$ as a risk factor for $\mathrm{CTS}^{5-7}$ and particularly for UNE. ${ }^{8}$ Recent studies, however, indicate that patients with DM are more susceptible to $\mathrm{CN}$ than non-diabetics, and thus might be affected to a greater extent by CTS and possibly also UNE. ${ }^{49}$ 
The exact etiology of CTS is not fully understood, although it is widely agreed that it is caused by a compression of the median nerve in the carpal tunnel in the wrist. ${ }^{10}{ }^{11}$ Likewise, the ulnar nerve is prone to compression when passing through the cubital tunnel on the medial side of the elbow causing UNE. ${ }^{13}$ The effects of DM on the peripheral nerves in the upper extremity are multifactorial, and pathologic metabolic and vascular factors have been proposed. ${ }^{41415}$ Consequently, once affected by DM, the nerve is more vulnerable to compression and at increased risk for $\mathrm{CN} .{ }^{416-18}$ Moreover, several researchers have argued that CNs among patients with DM are only a part of a more complex syndrome, sometimes referred to as 'the diabetic hand', including diagnoses such as Dupuytren's contracture, trigger finger, and limited joint mobility. ${ }^{19}$

Earlier studies on the relation between CTS and DM have been summarized in a meta-analysis. ${ }^{9}$ As they have mostly been of case-control or cross-sectional design, the amount of large, longitudinal cohort data is to our knowledge limited, especially concerning UNE. ${ }^{9}{ }^{20}$ Thus, the aim of the present population-based, longitudinal study was to explore the associations between baseline DM and incident CTS and UNE during long-term follow-up in a large cohort of more than 30000 mostly middle-aged individuals from southern Sweden.

\section{RESEARCH DESIGN AND METHODS}

\section{Study population}

A large, population-based register from southern Sweden, the Malmö Diet and Cancer Study (MDCS), thoroughly described in previous publications, ${ }^{21}{ }^{22}$ was used in this study. Briefly, the MDCS cohort of 30446 individuals aged 46-73 years (two-thirds women) was recruited between 1991 and $1996 .{ }^{21}$ Attendees were screened at baseline for cardiovascular risk factors and underwent clinical examination and laboratory assessment under fasting conditions (figure 1).

A random $50 \%$ of the original MDCS cohort were invited to rescreening for carotid artery disease in 1992 1994 and 6103 subjects attended. In this cohort, referred to as the MDCS-Cardiovascular Cohort (MDCS-CC), 5508 participants had additional blood tests drawn, including HbA1c (originally \%, presented in the article as mmol/ $\mathrm{mol})$ and fasting plasma glucose $(\mathrm{mmol} / \mathrm{L})$.

\section{Anthropometry, clinical examinations, and laboratory measurements}

All participants had their height and weight measured at baseline. Body mass index (BMI) was calculated as (weight $[\mathrm{kg}]$ )/ (height $\times$ height $[\mathrm{m}]$ ). Prevalent DM was defined as either a self-reported physician's diagnosis of DM, the use of antidiabetic medication, or a fasting whole blood glucose $>6.0 \mathrm{mmol} / \mathrm{L}$ at baseline. Furthermore, data on both prevalent and incident DM were validated by linking an attendee's unique personal identity number to six other national and local registers, previously described in detail. ${ }^{23}$ Smoking was self-reported by a questionnaire and defined as a current smoker or the use of cigarettes during the last year. Hypertension was defined as having a systolic blood pressure (BP) $\geq 140 \mathrm{~mm}$ $\mathrm{Hg}$ or diastolic BP $\geq 90 \mathrm{~mm} \mathrm{Hg}$, measured in a supine position using a mercury column sphygmomanometer. ${ }^{24}$ The use of antihypertensive treatment was self-reported. Alcohol consumption was self-reported in the questionnaire and converted into grams of alcohol consumed per day (g/day). Laboratory analyses were conducted at Malmö University Hospital, Department of Clinical Chemistry, after an overnight fast.

\section{Definition of endpoints and ascertainment}

Data on primary endpoints, that is, a diagnosis of either CTS or UNE during follow-up, were obtained through

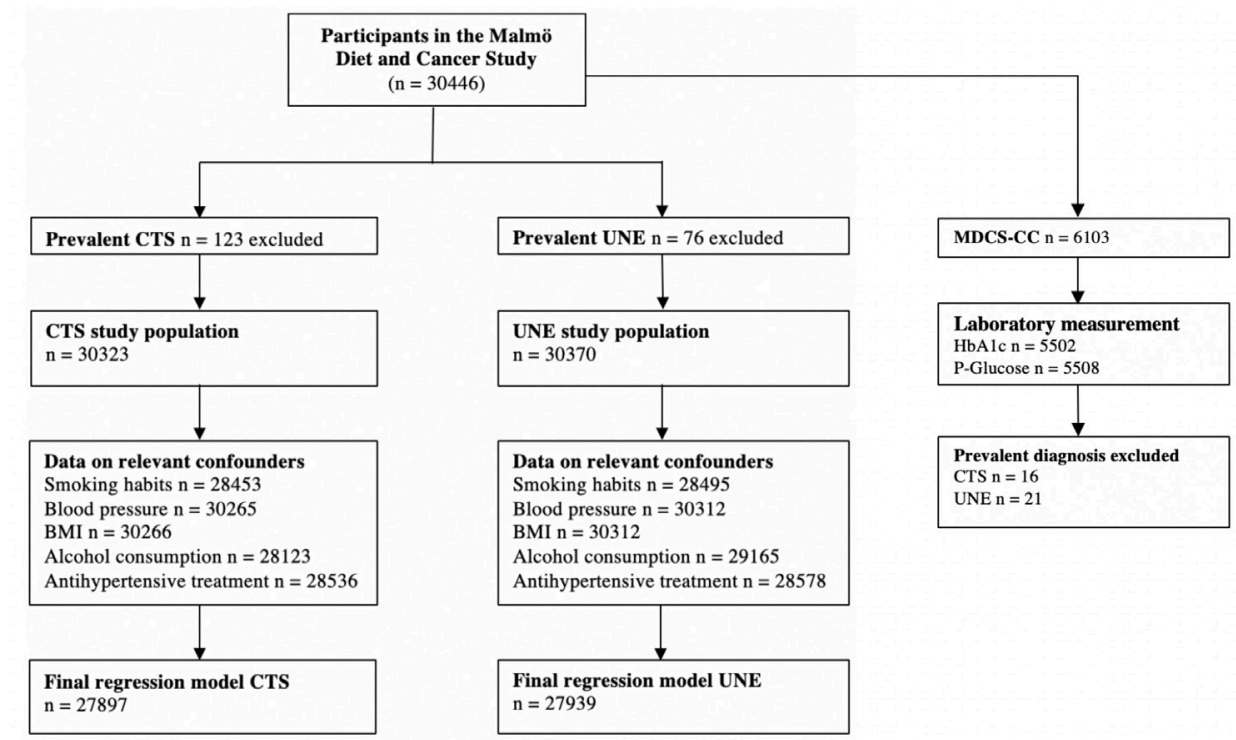

Figure 1 Derivation of the study cohort from Malmö Diet and Cancer Study. BMI, body mass index; CTS, carpal tunnel syndrome; MDCS-CC, Malmö Diet and Cancer Study-Cardiovascular Cohort; UNE, ulnar nerve entrapment. 
Swedish National Patient Registers administered by the National Board of Health and Welfare (http:// socialstyrelsen.se/english) including the inpatient register from study start, the day surgery register from 1997, and the outpatient register from 2000, using the participants' unique personal identity number. ${ }^{25}$ Diagnoses of CTS were retrieved using the International Classification of Diseases version 8, 9 or 10 with the following codes: 352.02; 357.01; 354A; G560. Diagnoses of UNE were retrieved using the following codes: 352.01; 3570; 354C; G562. Operation and surgical codes were not available for this study; only clinical, hospital-based CTS and UNE diagnoses were used. The time to event variable was calculated from baseline to either an endpoint diagnosis, death, emigration, or end of follow-up on 31 December 2016.

\section{Statistical analyses}

All statistical analyses were made using IBM SPSS statistics for Mac V.25 (SPSS) and a two-sided $p$ value $<0.05$ was considered significant.

Basic participant characteristic variables were presented as mean and median with SD and IQR for quantitative normally and non-normally distributed variables, respectively. The Student's t-test was used to calculate the differences in continuous variables if normally distributed, and, if skewed, the Mann-Whitney U test was used. For dichotomous variables, count and proportion $(\%)$ were used, and the $\chi^{2}$ test was used for group comparisons.

For endpoint assessment, Cox proportional hazards regression models were used. Prevalent DM at baseline was related to incident CTS and UNE first using a crude model, adjusting only for age at study entry and sex. A second multivariate Cox regression model was adjusted for age at study entry, sex, and factors previously related to $\mathrm{CN} ;{ }^{6} 8112627$ that is, BMI, current smoking, alcohol consumption, use of antihypertensive medication, and hypertension, converted to a dichotomous variable using BP levels described above. HRs were expressed with a CI of $95 \%$ with participants without DM at baseline as a reference. Cumulative incidences of CTS and UNE were calculated using Kaplan-Meier (KM) plots, and log-rank test was used to test group differences in event-free time. The proportional hazard assumption was confirmed by visual inspection of KM survival curves and log-log plots.

To assess potential effects of HbAlc and plasma glucose on incident CTS and UNE, a binary logistic regression model, adjusted for sex and age at study entry, was used. Levels of HbAlc (converted to $\mathrm{mmol} / \mathrm{mol}$ ) and plasma glucose $(\mathrm{mmol} / \mathrm{L})$ were treated as continuous variables. ORs with $95 \%$ CI were calculated for one unit increase in HbA1c and plasma glucose, respectively.

\section{RESULTS}

\section{Baseline characteristics}

At baseline, the mean age was 57 (SD 7.6) years. Participants with prevalent CTS $(n=123)$ or UNE $(n=76)$ at baseline were excluded from further analysis. The prevalence of DM at baseline investigation was $4.5 \% \quad(\mathrm{n}=1379)$ in CTS group and $4.6 \% \quad(\mathrm{n}=1391)$ in the UNE group (tables 1 and 2).

\section{Carpal tunnel syndrome}

In total, 1081 participants developed CTS (3.6\%; $1081 / 30$ 323) during a median follow-up of 21.4 (IQR 5.9 ) years, corresponding to an incidence of 1.84 cases per 1000 person-years, which is in line with previous studies. ${ }^{10}$ Median follow-up was 21.6 (IQR 5.5) years for participants without DM and 18.1 (IQR 11.1) years for participants with DM.

At baseline, participants subsequently diagnosed with incident CTS showed higher BMI $(\mathrm{p}<0.001)$, lower alcohol consumption $(\mathrm{p}=0.041)$, and lower prevalence of hypertension $(\mathrm{p}=0.008)$ compared with participants

Table 1 Baseline characteristics with all subjects and stratified with regard to CTS

\begin{tabular}{lcccc}
\hline Characteristics & $\begin{array}{l}\text { All subjects } \\
(\mathbf{n = 3 0 3 2 3 )}\end{array}$ & $\begin{array}{l}\text { Without CTS } \\
(\mathbf{n = 2 9 2 4 2 )}\end{array}$ & $\begin{array}{l}\text { Incident CTS } \\
(\mathbf{n = 1 0 8 1 )}\end{array}$ & P value* $^{*}$ \\
\hline Age, years (SD) & $57.5(7.6)$ & $57.6(7.6)$ & $55.7(7.5)$ & $<0.001$ \\
\hline Sex (n, \% male) & $12099(40)$ & $11804(40)$ & $293(27)$ & $<0.001$ \\
\hline BMI (kg/m²) (IQR) & $25.3(20.3-30.3)$ & $25.3(20.3-30.3)$ & $26.3(20.9-31.7)$ & $<0.001$ \\
\hline Current smoking (n, \%) & $8050(28)$ & $7769(28)$ & $281(27)$ & 0.46 \\
\hline Systolic blood pressure, mm Hg, (IQR) & $140(112-168)$ & $140(112-168)$ & $138(112-162)$ & $<0.001$ \\
\hline Diastolic blood pressure, mm Hg, (IQR) & $85(75-95)$ & $85(75-95)$ & $84(72-96)$ & 0.002 \\
\hline Antihypertensive treatment (n, \%) & $5273(18.5)$ & $5094(18.5)$ & $179(17.3)$ & 0.34 \\
\hline Prevalent diabetes (n, \%) & $1379(4.5)$ & $1291(4.4)$ & $88(8.1)$ & 0.001 \\
\hline Alcohol consumption (g/day) (IQR) & $7.2(1.5-15.2)$ & $7.2(1.5-15.3)$ & $6.7(1.3-13.8)$ & 0.041 \\
\hline
\end{tabular}

$P$ value for group comparison between subjects without CTS and with incident CTS.

${ }^{*} \mathrm{P}$ value for group comparison; independent sample t-test used for age, Mann-Whitney $\mathrm{U}$ test used for BMI, systolic and diastolic blood pressure (BP), $\chi^{2}$ test for dichotomous variable. Participants with prevalent CTS are excluded.

BMI, body mass index; CTS, carpal tunnel syndrome. 
Table 2 Baseline characteristics with all subjects and stratified with regard to UNE

\begin{tabular}{lcccc}
\hline Characteristics & $\begin{array}{l}\text { All subjects } \\
(\mathbf{n}=\mathbf{3 0 3 7 0 )}\end{array}$ & $\begin{array}{l}\text { Without UNE } \\
(\mathbf{n}=\mathbf{3 0 1 4 7 )}\end{array}$ & $\begin{array}{l}\text { Incident UNE } \\
(\mathbf{n}=223)\end{array}$ & P value* $^{*}$ \\
\hline Age, years (SD) & $57.5(7.6)$ & $57.5(7.6)$ & $54.5(6.8)$ & 0.001 \\
\hline Sex (n, \% male) & $12079(40)$ & $11993(39)$ & $86(38)$ & 0.70 \\
\hline BMI (kg/m²) (IQR) & $25.3(20.3-30.3)$ & $25.3(20.3-30.3)$ & $26.0(20.4-31.4)$ & 0.004 \\
Current smoking (n, \%) & $8054(28.3)$ & $7975(28.2)$ & $79(37.1)$ & 0.004 \\
\hline Systolic blood pressure, mm Hg, (IQR) & $140(112-168)$ & $140(112-168)$ & $132(102-162)$ & $<0.001$ \\
\hline Diastolic blood pressure, mm Hg, (IQR) & $85(75-95)$ & $85(75-95)$ & $82(70-84)$ & 0.031 \\
\hline Antihypertensive treatment (n, \%) & $5287(18.5)$ & $5251(18.5)$ & $36(16.9)$ & 0.55 \\
\hline Prevalent diabetes (n, \%) & $1391(4.6)$ & $1372(4.6)$ & $19(8.5)$ & 0.005 \\
\hline Alcohol consumption (g/day) (IQR) & $7.2(1.5-15.2)$ & $7.2(1.5-15.2)$ & $7.2(1.3-15.5)$ & 0.99 \\
\hline
\end{tabular}

$P$ value for group comparison between subjects without UNE and with incident UNE.

${ }^{*} \mathrm{P}$ value for group comparison; independent sample t-test used for age, Mann-Whitney U test used for BMI, systolic and diastolic blood pressure (BP), $\chi^{2}$ test for dichotomous variable. Participants with prevalent UNE are excluded.

BMI, body mass index; UNE, ulnar nerve entrapment.

without incident CTS, whereas there were no significant differences between groups in smoking habits $(\mathrm{p}=0.46)$ or use of antihypertensive treatment $(\mathrm{p}=0.34)$. DM was more frequent at baseline among the population with incident CTS $(\mathrm{p}<0.001)$ (table 1$)$.

Using univariate KM plots, there was a shorter CTS-free time in participants with DM compared with participants without DM (log-rank p<0.0001) (figure 2).

In the first Cox regression model, only adjusted for sex and age at study entry, DM was independently associated with incident CTS (HR 2.52; $95 \%$ CI 1.99 to 3.18, $\mathrm{p}<0.0001)$. In the multivariate model, adjusting for sex, age at study entry, alcohol consumption, BMI, hypertension, use of antihypertensive treatment, and smoking, prevalent DM at baseline was still independently associated with incident CTS (HR 2.10; 95\% CI 1.65 to $2.70, \mathrm{p}<0.0001)$. Furthermore, higher BMI was associated with incident CTS, while hypertension, smoking and alcohol consumption did not show any association with incident CTS (table 3).

In the MDCS-CC subcohort, 190 participants developed CTS during the study period. Using a logistic regression model adjusted for sex and age at study entry, higher HbAlc (OR 1.029; 95\% CI 1.016 to 1.041, $\mathrm{p}<0.001$ ) and plasma glucose (OR 1.154; $95 \%$ CI 1.081 to $1.232, \mathrm{p}<0.001)$ were both associated with the development of CTS. Adjusting for additional confounders did not affect these results (data not shown).
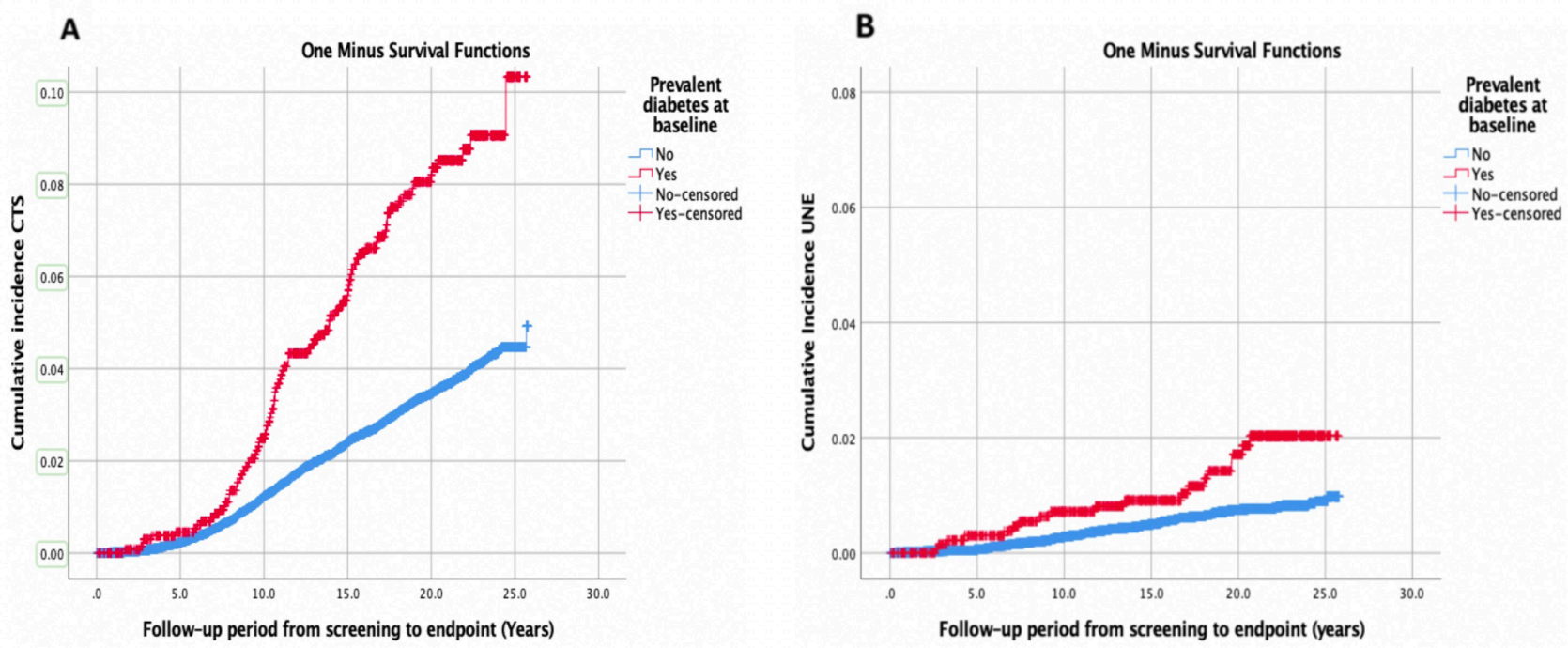

Figure 2 Cumulative incident CTS (A) and UNE (B), stratifying for DM during a follow-up of 25 years using Kaplan-Meier survival curves. Log-rank test for difference in survival distributions for CTS $p<0.0001$ and UNE $p<0.0001$. CTS, carpal tunnel syndrome; DM, diabetes mellitus; UNE, ulnar nerve entrapment. 
Table 3 Multivariable Cox regression analysis with HRs for incident CTS and UNE in relation to diabetes mellitus

\begin{tabular}{|c|c|c|c|c|}
\hline \multirow[b]{2}{*}{ Variable } & \multicolumn{2}{|l|}{ Model I* } & \multicolumn{2}{|l|}{ Model II† } \\
\hline & HR $(95 \% \mathrm{Cl})^{*}$ & $P$ value & HR $(95 \% \mathrm{Cl}) \dagger$ & $P$ value \\
\hline \multicolumn{5}{|l|}{ CTS $(n=1081)$} \\
\hline Prevalent DM & 2.52 (1.99 to 3.18 ) & $<0.0001$ & 2.10 (1.65 to 2.70$)$ & $<0.0001$ \\
\hline Age & 0.98 (0.97 to 0.99$)$ & $<0.0001$ & 0.98 (0.97 to 0.99$)$ & $<0.0001$ \\
\hline Sex & 1.69 (1.47 to 1.95$)$ & $<0.0001$ & 1.69 (1.45 to 1.96$)$ & $<0.0001$ \\
\hline Body mass index & - & - & 1.07 (1.06 to 1.08$)$ & $<0.0001$ \\
\hline Hypertension & - & - & 0.98 (0.85 to 1.12$)$ & 0.73 \\
\hline Current smoking & - & - & 1.06 (0.92 to 1.23$)$ & 0.38 \\
\hline Alcohol consumption & - & - & 0.99 (0.99 to 1.00$)$ & 0.18 \\
\hline Antihypertensive treatment & - & - & 1.04 (0.88 to 1.24$)$ & 0.62 \\
\hline \multicolumn{5}{|l|}{ UNE $(n=223)$} \\
\hline Prevalent DM & 2.51 (1.49 to 4.19$)$ & $<0.001$ & 2.20 (1.30 to 3.74$)$ & 0.003 \\
\hline Age & 0.95 (0.93 to 0.97$)$ & $<0.0001$ & $0.96(0.94$ to 0.98$)$ & $<0.001$ \\
\hline Sex & 0.87 (0.66 to 1.16$)$ & 0.35 & 0.88 (0.65 to 1.19$)$ & 0.39 \\
\hline Body mass index & - & - & 1.06 (1.02 to 1.09$)$ & 0.001 \\
\hline Hypertension & - & - & 0.87 (0.64 to 1.19$)$ & 0.39 \\
\hline Current smoking & - & - & 1.60 (1.21 to 2.15$)$ & 0.001 \\
\hline Alcohol consumption & - & - & 0.99 (0.98 to 1.01$)$ & 0.68 \\
\hline Antihypertensive treatment & - & - & 1.04 (0.70 to 1.54$)$ & 0.83 \\
\hline
\end{tabular}

${ }^{*}$ Adjusted for sex and age at study entry.

†Adjusted for sex, age at study entry, alcohol consumption, body mass index (BMI), hypertension, the use of antihypertensive treatment, and smoking.

CTS, carpal tunnel syndrome; DM, diabetes mellitus; UNE, ulnar nerve entrapment.

\section{Ulnar nerve entrapment}

In total, 223 participants developed UNE $(0.7 \%$; 223/30 370) during a median follow-up of 21.6 (IQR 5.1 ) years, corresponding to an incidence of 0.37 cases per 1000 person-years, a figure in line with previous studies. ${ }^{13}$ Median follow-up was 21.7 (IQR 4.7) years for participants without DM and 19.3 (IQR 10.3) years for participants with DM.

At baseline, participants subsequently diagnosed with UNE had higher BMI $(\mathrm{p}=0.004)$, lower prevalence of hypertension $(\mathrm{p}=0.014)$, and were more often smokers $(\mathrm{p}=0.004)$ compared with participants without incident UNE. There were no differences in alcohol consumption $(\mathrm{p}=0.99)$ or use of antihypertensive treatment $(\mathrm{p}=0.55)$. $\mathrm{DM}$ was more frequent at baseline in the population with incident UNE $(\mathrm{p}<0.005)$ (table 2).

Using univariate KM plots, there was a shorter UNEfree time in participants with DM compared with participants without DM (log-rank $\mathrm{p}<0.0001)$ (figure 2).

In the first Cox regression model, only adjusted for sex and age at study entry, DM was independently associated with incident UNE (HR 2.51; 95\% CI 1.49 to $4.19, \mathrm{p}<0.001)$. In the multivariate Cox regression model, adjusting for sex, age at study entry, alcohol consumption, BMI, hypertension, use of antihypertensive treatment, and smoking, prevalent DM was independently associated with incident UNE (HR 2.20; 95\% CI 1.30 to
3.74, $\mathrm{p}=0.003)$. Furthermore, higher BMI and smoking were associated with incident UNE, whereas hypertension and alcohol consumption did not show any association with incident UNE (table 3).

In the MDCS-CC subcohort, 44 participants developed UNE during the study period. Using a logistic regression model adjusted for sex and age at study entry, neither higher HbA1c (OR 0.99, 95\% CI 0.961 to 1.039 , p=0.97) nor higher plasma glucose (OR $0.728,95 \%$ CI 0.455 to $1.165, \mathrm{p}=0.17$ ) was associated with development of UNE. Adjusting for additional confounders did not affect these results (data not shown).

\section{DISCUSSION}

\section{Principal findings}

This observational study presents evidence that DM is independently associated with the development of CTS and UNE during long-term follow-up of a middle-aged population from northern Europe. Furthermore, the association between DM at baseline and an increased risk for development of CTS and UNE during follow-up was not attenuated by adjustments for possible confounders, such as age at study entry, sex, BMI, alcohol consumption, smoking habits, hypertension, or use of antihypertensive treatment. To our knowledge, this is the first large-scale longitudinal cohort study addressing the influence of DM 
on the incidences of both CTS and UNE in a northern European population. Our results are in line with both a previous meta-analysis of CTS and $\mathrm{DM}^{9}$ and a smaller case-control study of UNE and DM. ${ }^{8}$

\section{The hyperglycemic nerve}

Several explanations have been presented as to why the peripheral nerve seems to be more susceptible to compression in the presence of DM. Proposed mechanisms include an already frail peripheral nerve due to chronic hyperglycemia altering intracellular metabolism. ${ }^{28-30}$ In the hyperglycemic state, the neuron and adjacent Schwann cells are unable to compensate for excess intracellular glucose, saturating the enzymes responsible for the homeostatic metabolism of glucose. This leads to accumulation of intracellular hyperosmotic proteins, for example, sorbitol, and ultimately leading to axonal degeneration and segmental demyelination. ${ }^{31}$ Hyperosmotic proteins might also trap fluid within the cell, eventually leading to edema and possibly nerve trunk swelling. ${ }^{4}$ Indeed, ultrasonic studies of the median nerve at wrist level, and in the tibial nerve, in patients with diabetes have shown a thicker cross-sectional area compared with in healthy controls. ${ }^{32} 33$

Furthermore, an intracellular excess of glucose in the peripheral nerve cells leads to increased oxidative stress due to increased mitochondrial production of reactive oxygen species, inducing cell damage and possible axonal degeneration; ${ }^{431} 34$ the latter making the diabetic nerve more susceptible to a compression trauma. ${ }^{18}$

Intracellular hyperglycemia also induces pathologic glycation of intracellular proteins, forming advanced glycation end products (AGE). AGEs accumulate both in the cell and in the extracellular matrix and compromise the diffusion of nutrients over the blood-nerve barrier. ${ }^{285}$ AGEs might also affect the surrounding tissue and have been associated with both Dupuytren's disease and limited joint mobility. ${ }^{28} 3637$ This might partially explain the more complex syndrome of the diabetic hand. ${ }^{19} 38$

Moreover, DM might also affect microvascular patterns in the peripheral nerve. There is evidence that both increased endoneurial capillary density and thickening of intraneural blood vessel basement membrane might be induced by DM. ${ }^{30}$ Data from biopsies of the posterior interosseous nerve just proximal to the wrist in patients with CTS suggest reduced microcirculation, upregulation of vascular endothelial growth factor, and a reduction in myelinated nerve fibers in patients with DM. ${ }^{18} 39$

Finally, sheer mechanical pressure in $\mathrm{CN}$ also affects the nerve with decreased blood supply and impaired venous return, further adding to hypoxia. ${ }^{14} 40$ Thus, in the presence of hyperglycemia, when an already susceptible frail and edematous nerve with low density of nerve fibers is compressed in, for example, the narrow carpal tunnel, the threshold for development of symptoms might be reached earlier compared with a healthy nerve. ${ }^{4}$
This might partly explain our results of increased risk for developing $\mathrm{CN}$ in the population with diabetes.

\section{The ulnar nerve}

If, and how, DM and hyperglycemia affect the ulnar and median nerves differently is not fully understood, partly owing to the fact that biopsies for obvious reasons are not available. Regarding UNE, there are to our knowledge no longitudinal cohort studies assessing DM as a potential risk factor. Several case studies have been published, but epidemiological studies addressing UNE are rare in comparison to CTS. ${ }^{4041}$ Our study revealed an increased risk for participants with DM to develop UNE.

In the MDCS-CC subcohort, elevated levels of fasting plasma glucose and HbAlc were only correlated to an increased risk of developing CTS, and not to UNE. There are few large population-based cohort studies relating plasma levels of glucose and HbAlc to incident CTS and UNE. On the other hand, there are several previous studies correlating high levels of HbAlc with polyneuropathy in subjects with $\mathrm{DM},{ }^{42}{ }^{43}$ although the effect of glycemic control has been debated at least in type 2 diabetes. ${ }^{30}$ Strict glycemic control effectively lowered the risk of polyneuropathy among subjects with type 1 diabetes, but not to the same extent in type 2 diabetes in earlier studies. ${ }^{30}$ In our results, poor glycemic control was associated with an increased risk for CTS, but not for UNE; suggesting that the median and ulnar nerves might be affected differently by hyperglycemia. Other factors related to DM, for example, insulin resistance or microvascular alterations, might be more important than glycemic control in itself for the development of UNE.

\section{Sex, hypertension, smoking, alcohol consumption, and BMI}

CTS occurred more commonly among women than men in accordance with previous studies, ${ }^{44}$ whereas the incidence of UNE did not differ between sexes.

At baseline, hypertension was less common in participants who developed CTS and UNE than among participants who did not. When included in the multivariate regression model, there were no associations with either CTS or UNE. Previous studies have proposed hypertension as a possible protective factor for $\mathrm{CN},{ }^{26}{ }^{27}$ but such effects were not supported by our results. A larger proportion of women, who had lower BP than men in the MDCS, ${ }^{45}$ might explain why hypertension was less common at baseline in the group with incident $\mathrm{CN}$. This would also explain why the effect of hypertension was attenuated when adjusting for sex in the Cox regression model.

Smoking has previously been described as a risk factor for developing both UNE and CTS. ${ }^{46}{ }^{47}$ Our results, both at baseline investigation and in the multivariate regression model, suggest that smoking is associated with an increased risk for UNE, but not for CTS.

Also, participants with incident CTS reported lower alcohol consumption than participants who did not develop CTS. The difference, however, did not remain 
significant in the regression model when adjusting for sex.

Finally, dyslipidemia and obesity are other possible causes of peripheral neuropathy, leading to both inflammation and oxidative stress. ${ }^{29}{ }^{34}$ In our study, individuals developing $\mathrm{CN}$ had a higher BMI at baseline compared with participants without incident CN. This corroborates previous results, suggesting BMI as an individual risk factor for $\mathrm{CN}$, regardless of hyperglycemia. ${ }^{44}$ Likewise, when included in the multivariate model, higher BMI was independently associated with both CTS and UNE, suggesting that both BMI and DM might be separate risk factors for development of $\mathrm{CN}$.

\section{Strengths and weaknesses of this study}

Although we adjusted for known confounders in the multivariate model, there is always a possibility that additional confounders, known or unknown, might have influenced study outcomes. However, our results implicating $\mathrm{DM}$ as a major risk factor are concurrent with several earlier studies on the subject, both cross-sectional and case-control studies, ${ }^{49}$ why it seems unlikely that residual confounding would be sufficient to alter our conclusions.

Furthermore, in all observational cohort studies there is always a risk for selection bias. Previous studies comparing individuals participating in the MDCS cohorts have shown lower mortality among participants compared with a control group. ${ }^{48}$ It is possible that participants with a chronic disease, such as DM, were more often examined by a physician, making it easier to mention symptoms of $\mathrm{CN}$ and thus increasing the incidence in the group with DM. However, the large numbers of individuals, randomly selected during several years, are factors protecting against both sample and detection bias.

Another limitation of this study is the lack of standardized diagnostic criteria for CTS and UNE. Since we used only hospital-based diagnoses from national registers, we were unable to support diagnoses with, for example, electrophysiological findings. Furthermore, we also lack data from the primary healthcare. On the other hand, as we use only hospital-based inpatient and outpatient data, all diagnoses have been established by specialists in the field, either hand surgeons or experienced orthopedic surgeons. Also, diagnostic criteria have not differed between participants with or without diabetes.

Moreover, occupational experience has previously been shown to affect the risk of CN development. ${ }^{5}$ Unfortunately, occupational data were not available in this study.

Finally, important strengths of the present study include the large number of middle-aged participants and the long follow-up of 21 years, making it one of the largest longitudinal population-based cohort studies addressing $\mathrm{DM}$ and $\mathrm{CN}$.

\section{Future research}

Unfortunately, our registers did not reliably stratify for type 1 diabetes and type 2 diabetes, making it impossible to calculate separate regression curves. At the time of baseline, definitions of different types of diabetes were not as stringent as they are today and classifications, such as 'insulin dependent' and 'non-insulin dependent' diabetes, were often used. How different types of diabetes affect the risk of incident $\mathrm{CN}$ is an obvious focus for future research. Likewise, how the metabolic syndrome, pre-diabetes and obesity affect the median and ulnar nerves is a future research target.

\section{CONCLUSION}

In conclusion, this study establishes DM as a major risk factor in the development of both CTS and UNE. Furthermore, a higher BMI is associated with both CTS and UNE. Finally, hyperglycemia seems to affect the median and ulnar nerves differently.

Contributors All stated authors made significant contributions to this article. MR, MZ and LBD designed the study and MR wrote the first draft. All authors contributed to the interpretation of the data, reviewed and accepted the final version before publishing.

Funding The Malmö Diet and Cancer Study was made possible by grants from the Swedish Cancer Society, the Swedish Medical Research Council, AFA Insurance, the Albert Påhlsson and Gunnar Nilsson Foundations and the Malmö City Council. This study was funded by the Swedish Diabetes Foundation, the Regional Agreement on Medical Training and Clinical Research (ALF) between Region Skåne and Lund University, Stig and Ragna Gorthons Foundation and local funds at Lund University.

Competing interests None declared.

Patient consent for publication Not required.

Ethics approval The study was approved by the Regional Ethical Review Board in Lund, Sweden (DNR: 2019-01433), and all participants provided written informed consent.

Provenance and peer review Not commissioned; externally peer reviewed.

Data availability statement Data may be obtained from a third party and are not publicly available. Original study data can be applied for by contacting the Steering Committee of the Malmö Diet and Cancer Study (data manager Anders Dahlin, email: anders.dahlin@med.lu.se).

Open access This is an open access article distributed in accordance with the Creative Commons Attribution Non Commercial (CC BY-NC 4.0) license, which permits others to distribute, remix, adapt, build upon this work non-commercially, and license their derivative works on different terms, provided the original work is properly cited, appropriate credit is given, any changes made indicated, and the use is non-commercial. See: http://creativecommons.org/licenses/by-nc/4.0/.

ORCID ID

Mattias Rydberg http://orcid.org/0000-0002-8249-8660

\section{REFERENCES}

1 World Health Organization. Global report on diabetes, 2016. Available: https://apps.who.int/iris/handle/10665/2048712019

2 Global Burden of Disease Collaborative Network. Global burden of disease study 2017 (GBD 2017) incidence, prevalence, and years lived with disability 1990-2017. Seattle, United States: Institute for Health Metrics and Evaluation (IHME), 2018.

3 Padua L, Coraci D, Erra C, et al. Carpal tunnel syndrome: clinical features, diagnosis, and management. Lancet Neurol 2016;15:1273-84.

4 Rota E, Morelli N. Entrapment neuropathies in diabetes mellitus. World J Diabetes 2016;7:342-53.

5 Harris-Adamson C, Eisen EA, Dale AM, et al. Personal and workplace psychosocial risk factors for carpal tunnel syndrome: a pooled study cohort. Occup Environ Med 2013;70:529-37.

6 Shiri R, Heliövaara M, Moilanen L, et al. Associations of cardiovascular risk factors, carotid intima-media thickness and manifest atherosclerotic vascular disease with carpal tunnel syndrome. BMC Musculoskelet Disord 2011;12:80. 
7 Hendriks SH, van Dijk PR, Groenier KH, et al. Type 2 diabetes seems not to be a risk factor for the carpal tunnel syndrome: a case control study. BMC Musculoskelet Disord 2014;15:346.

8 Bartels RHMA, Verbeek ALM. Risk factors for ulnar nerve compression at the elbow: a case control study. Acta Neurochir 2007;149:669-74.

9 Pourmemari $\mathrm{MH}$, Shiri R. Diabetes as a risk factor for carpal tunnel syndrome: a systematic review and meta-analysis. Diabet Med 2016;33:10-16.

10 Urits I, Gress K, Charipova K, et al. Recent advances in the understanding and management of carpal tunnel syndrome: a comprehensive review. Curr Pain Headache Rep 2019;23:70.

11 Doughty CT, Bowley MP. Entrapment neuropathies of the upper extremity. Med Clin North Am 2019;103:357-70.

12 Palmer BA, Hughes TB. Cubital tunnel syndrome. J Hand Surg Am 2010;35:153-63.

13 Osei DA, Groves AP, Bommarito K, et al. Cubital tunnel syndrome: incidence and demographics in a national administrative database. Neurosurgery 2017;80:417-20.

14 Tapadia M, Mozaffar T, Gupta R. Compressive neuropathies of the upper extremity: update on pathophysiology, classification, and electrodiagnostic findings. J Hand Surg Am 2010;35:668-77.

15 Callaghan B, Feldman E. The metabolic syndrome and neuropathy: therapeutic challenges and opportunities. Ann Neurol 2013;74:397-403

16 Upton AR, McComas AJ. The double crush in nerve entrapment syndromes. Lancet 1973;2:359-62.

17 Dahlin LB, Meiri KF, McLean WG, et al. Effects of nerve compression on fast axonal transport in streptozotocin-induced diabetes mellitus. Diabetologia 1986;29:181-5.

18 Thomsen NOB, Mojaddidi M, Malik RA, et al. Reduced myelinated nerve fibre and endoneurial capillary densities in the forearm of diabetic and non-diabetic patients with carpal tunnel syndrome. Acta Neuropathol 2009;118:785-91.

19 Fitzgibbons PG, Weiss A-PC. Hand manifestations of diabetes mellitus. J Hand Surg Am 2008;33:771-5.

20 Jang JE, Kim YT, Park BK, et al. Subclinical ulnar neuropathy at the elbow in diabetic patients. Ann Rehabil Med 2014;38:64-71.

21 Berglund G, Elmstähl S, Janzon L, et al. The Malmo diet and cancer study. design and feasibility. J Intern Med 1993;233:45-51.

22 Berglund G, Nilsson P, Eriksson KF, et al. Long-term outcome of the Malmö preventive project: mortality and cardiovascular morbidity. J Intern Med 2000;247:19-29.

23 Enhörning S, Wang TJ, Nilsson PM, et al. Plasma copeptin and the risk of diabetes mellitus. Circulation 2010;121:2102-8.

24 Williams B, Mancia G, Spiering W, et al. 2018 ESC/ESH guidelines for the management of arterial hypertension. Eur Heart $J$ 2018;39:3021-104.

25 Ludvigsson JF, Andersson E, Ekbom A, et al. External review and validation of the Swedish national inpatient register. BMC Public Health 2011;11:450-50.

26 Szabo RM, Gelberman RH, Williamson RV, et al. Effects of increased systemic blood pressure on the tissue fluid pressure threshold of peripheral nerve. J Orthop Res 1983;1:172-8.

27 Guan W, Lao J, Gu Y, et al. Case-control study on individual risk factors of carpal tunnel syndrome. Exp Ther Med 2018;15:2761-6.

28 Sessions J, Nickerson DS. Biologic basis of nerve decompression surgery for focal entrapments in diabetic peripheral neuropathy. J Diabetes Sci Technol 2014;8:412-8.
29 Feldman EL, Nave K-A, Jensen TS, et al. New horizons in diabetic neuropathy: mechanisms, bioenergetics, and pain. Neuron 2017;93:1296-313

30 Feldman EL, Callaghan BC, Pop-Busui R, et al. Diabetic neuropathy. Nat Rev Dis Primers 2019;5:41.

31 Tomlinson DR, Gardiner NJ. Glucose neurotoxicity. Nat Rev Neurosci 2008;9:36-45.

32 Watanabe $\mathrm{T}$, Ito $\mathrm{H}$, Morita $\mathrm{A}$, et al. Sonographic evaluation of the median nerve in diabetic patients: comparison with nerve conduction studies. J Ultrasound Med 2009;28:727-34.

33 Singh K, Gupta K, Kaur S. High resolution ultrasonography of the tibial nerve in diabetic peripheral neuropathy. $J$ Ultrason 2017:17:246-52.

34 Eid S, Sas KM, Abcouwer SF, et al. New insights into the mechanisms of diabetic complications: role of lipids and lipid metabolism. Diabetologia 2019;62:1539-49.

35 Shimizu F, Sano Y, Haruki H, et al. Advanced glycation endproducts induce basement membrane hypertrophy in endoneurial microvessels and disrupt the blood-nerve barrier by stimulating the release of TGF- $\beta$ and vascular endothelial growth factor (VEGF) by pericytes. Diabetologia 2011;54:1517-26.

36 Takase F, Mifune Y, Inui A, et al. Association of advanced glycation end products in Dupuytren disease. J Orthop Surg Res 2018;13:143.

37 Rosenbloom AL, Silverstein JH. Connective tissue and joint disease in diabetes mellitus. Endocrinol Metab Clin North Am 1996;25:473-83

38 Papanas N, Maltezos E. The diabetic hand: a forgotten complication? J Diabetes Complications 2010;24:154-62.

39 Mojaddidi MA, Ahmed MS, Ali R, et al. Molecular and pathological studies in the posterior interosseous nerve of diabetic and nondiabetic patients with carpal tunnel syndrome. Diabetologia 2014:57:1711-9.

40 Sözen T, Bașaran Nursel Çalık, Tınazlı M, et al. Musculoskeletal problems in diabetes mellitus. Eur J Rheumatol 2018:5:258-65.

41 Acosta JA, Hoffman SN, Raynor EM, et al. Ulnar neuropathy in the forearm: a possible complication of diabetes mellitus. Muscle Nerve 2003;28:40-5.

42 Lai Y-R, Chiu W-C, Huang C-C, et al. HbA1C variability is strongly associated with the severity of peripheral neuropathy in patients with type 2 diabetes. Front Neurosci 2019;13:90.

43 Perkins BA, Greene DA, Bril V. Glycemic control is related to the morphological severity of diabetic sensorimotor polyneuropathy. Diabetes Care 2001;24:748-52.

44 Becker J, Nora DB, Gomes I, et al. An evaluation of gender, obesity, age and diabetes mellitus as risk factors for carpal tunnel syndrome. Clin Neurophysiol 2002;113:1429-34.

45 Smith JG, Platonov PG, Hedblad B, et al. Atrial fibrillation in the Malmö diet and cancer study: a study of occurrence, risk factors and diagnostic validity. Eur J Epidemiol 2010;25:95-102.

46 Hulkkonen S, Auvinen J, Miettunen J, et al. Smoking is associated with ulnar nerve entrapment: a birth cohort study. Sci Rep 2019;9:9450-50

47 Hulkkonen S, Auvinen J, Miettunen J, et al. Smoking as risk factor for carpal tunnel syndrome: a birth cohort study. Muscle Nerve 2019;60:299-304.

48 Manjer J, Carlsson S, Elmståhl S, et al. The Malmö diet and cancer study: representativity, cancer incidence and mortality in participants and non-participants. Eur J Cancer Prev 2001;10:489-99. 